\title{
The American Academic Profession
}

\section{Future Challenges}

\section{Philip G. Altbach and Martin J. Finkelstein}

Philip G. Altbach is professor of higher education and director of the Center for International Higher Education at Boston College. Martin J. Finkelstein is director of the New Jersey Institute for Collegiate Teaching and Learning and professor of education at Seton Hall University. Address: Alfieri Hall, Seton Hall University, South Orange, NJ 07079. Fax: (201) 761-9758

$\mathrm{T}$ he academic profession worldwide is faced with significant problems as we approach the 21 st century. In our view, the following issues constitute some of the major challenges facing the American professoriate in the coming period. Similar factors affect other countries as well.

Economic shifts. The United States is moving from an industrial to an information-based economy and finds itself now competing in global markets. This has placed a premium on the preparation of a competitive work force; and colleges and universities and their faculties will find it increasingly necessary to orient their work, especially their teaching, to these objectives.

Technological shifts. The past five years in particular have witnessed a revolution in the dominant technology of academic work. Scholars increasingly rely on digital technology for accessing information and for communicating with colleagues and students. Teaching practices have historically proven extremely resistant to change, but indications are that new technologies are gaining acceptance in the classroom as well. For example, in the early 1990s, barely 10 percent of the professoriate used digital technology in their teaching; by 1995 that figure had jumped to 30 percent.

\section{American faculty face a bewildering mix of external forces that are beginning to change the rules governing academic careers and the expectations for aca- demic work.}

In the last quarter century, then, the vast majority of the American faculty faced a bewildering mix of external forces that are already beginning to change the rules governing academic careers and the expectations for academic work. Thus, while American academics continue by and large to be satisfied with their careers and the intrinsic qualities of academic work, factors such as a move to regulate workloads, tenure reviews, static salary growth, and a declining job market have all affected morale, and have generated a growing list of complaints.

\section{Current Challenges and Future Trends}

Unquestionably, the post-World War II "golden age" of the professoriate is at an end, and general conditions for the profession are changing in ways we do not yet fully understand. The following elements are part of the equation.

- Accountability will inevitably increase. Professors, once used to considerable autonomy in shaping their research, teaching, and their career options, will be increasingly constrained by the needs of employing institutions and subject to the measurement of output. Academic labor will be more carefully monitored and controlled.

- There will be a greater emphasis on teaching, although research productivity will remain the "gold standard." There has been a strong demand to reconfigure the system of academic rewards and to "open up" the system. The quality of teaching will be emphasized more, and it is likely that most faculty will do more teaching. Average teaching loads will increase.

- While the tenure system will not be abolished, it may be circumvented for many entering the profession. It is interesting that as the demands for the abolition of tenure that were common in the 1970 have abated, and a significant proportion of the full-time professoriate is tenured — an artifact of the aging of the profession"tenure track" positions are becoming less of the norm. There has been a rapid expansion of part-time faculty who have no possibility of regular appointments. Alternative career paths are being proposed and even implemented. Renewable contracts and long-term nontenure track positions are increasingly common. It is likely that these trends will increase as institutions strive for greater flexibility in resource allocation in the face of continued financial difficulties. The proportion of full-time tenure-track and tenured faculty will drop.

- Pressures to generate external funding will continue to increase, mainly in the research university sector. Academics have been asked to obtain funds through consulting, service to local industry and commerce, research, and other revenue-generating schemes. As academic institutions, especially in the public sector, find their budgets constrained, they seek other funding sources-and this will inevitably involve the professoriate. The demand for "university-industry linkages," common in higher education, is a part of 
this trend.

- The changes in research funding are not only indicative of other changes in the fiscal reality for higher education, but of other changes as well. Basic research is less emphasized as government funding diminishes and as the quest for "results" and immediate payoff takes precedent. For a half-century or more, universities were seen as the home of basic research-scientific research that would yield results in the long term but might have little immediate benefit. Funders are now less willing to support this kind of research. Accountability for research results is an increasing part of the pattern.

- The academic profession will increasingly lose power in the context of accountability and budgetary difficulties. In a difficult job market with limited mobility at the upper levels of the profession, academics are simply at a disadvantage. Those who have control over the budget will gain the upper hand-senior administrators will inevitably wield more authority, and the faculty will have less control over the university. One of the implications of this trend will be a lessening of autonomy.

- The differentiation between the "haves" and the "have nots" among institutions and in the academic profession, will continue, and perhaps even become exacerbated. The "research cadre"-those senior professors located mainly at the top 50 to 75 American universities, with a strong commitment to research, access to external funding, and low teaching loads-will find that their working conditions may deteriorate modestly, but that they will be able to continue functioning with minimal deterioration. The significant declines will occur at the second tier institutions. It is likely that the system will be further segmented by the expansion in the number of "non-tenure-track" full-time contract faculty hired mainly to teach, and of the continued growth of part-time faculty, creating a "three-class" professoriate.

- The sense of community, on the decline since the 1950s, will further deteriorate as the professoriate is divided demographically and by competing interests, increasingly differentiated institutions, and other forces.

These factors do not constitute a revolution in the academic profession, and we foresee academic life in the American university continuing on largely as before. Yet, the pressures on the academic profession will be unprecedented and significant change will inevitably take place. The new realities will affect different segments of the profession in different ways-but there is no doubt that we are in a period of challenge.

\section{The World Bank and UNESCO on Higher Education}

\section{Rollin Kent}

Rollin Kent is a professor in the Departamento de Investigaciones Educativas, Centro de Investigación y Estudios Avanzados, San Borja, México. Address: Departamento de Investigaciones Educativas, Centro de Investigación y Estudios Avanzados, San Borja 938, México, D.F. 03100. Tel: (525) 559-4232; fax: (525) 575-0320; e-mail: RKENT@UDLAPVMS.PUE.UDLAP.MX

$I^{n}$ $\mathrm{n}$ the mid-1990s, the policy debate on higher education has moved to the international arena. Multilateral lending organizations have spurred the debate, as illustrated by the World Bank's 1994 publication, Higher Education: The Lesson of Experience. In addition, UNESCO has been active in promoting international debate through its recent publication, Policy Paper for Change and Development in Higher Education. How do these positions compare in terms of their diagnosis of current problems in higher education and their prescriptions?

\section{The Diagnosis}

The starting point for both positions is that higher education today is in crisis. Both papers agree that the current situation is not sustainable in the medium and long term. According to the World Bank, higher education is in crisis throughout the world in terms of: low quality, because of rapid enrollment growth under conditions of limited resources; inefficiency, in terms of inappropriate use of public resources in higher education, high dropout rates, and program duplication; and inequity, because "public subsidies as a proportion of unit costs of higher education often far exceed the subsidies to primary and secondary education." The question of management and institutional leadership stands out as well. There can be no doubt that without serious attention to the institutional level - that is, management, leadership, the use and accountability of public resources, etc.-little progress can be expected in higher education reform.

UNESCO points out three important trends throughout the world: enormous quantitative expansion, which has nonetheless not led to increased equality of access and has not resulted in a proportionally large production of engineers and scientists; ${ }^{1}$ inadequate diversification of institutions, and academic programs that do not comply with minimum standards and have not led to significant educational innovations; and expansion in an increasingly constrained financial environment, where spending per student has not kept pace with the growing numbers of students 